www.jmscr.igmpublication.org

Index Copernicus Value: 79.54

ISSN (e)-2347-176x ISSN (p) 2455-0450

crossref DOI: https://dx.doi.org/10.18535/jmscr/v7i3.247

\title{
Incidence of Hypothyroidism after Hemithyroidectomy: A retrospective study in a tertiary care center in eastern India
}

\author{
Authors \\ Dr Chitta Ranjan Sarangi ${ }^{1}$, Dr Arun Kumar Mohanty ${ }^{2 *}$ \\ ${ }^{1}$ Associate Professor, ${ }^{2}$ Assistant Professor \\ Department of Endocrine Surgery, SCB Medical College, Cuttack, Odisha, India \\ *Corresponding Author \\ Dr Arun Kumar Mohanty \\ Mobile no: 9437031992, Email:drsidharth74@gmail.com
}

\begin{abstract}
Background and Aim: Development of hypothyroidism following hemithyroidectomy, although underappreciated, its detection prevents further complications and saves the retained lobe of thyroid to a great extent.

Methods: A study was conducted amongst 480 patients who had undergone Hemithyroidectomy in the Department of Experimental /Endocrine Surgery of SCB Medical College \& Hospital, Cuttack (Odisha) from 2012 to 2018 to determine the incidence of Hypothyroidism.

Results: It was observed that $15 \%$ of cases developed overt and 5.4\% developed sub-clinical hypothyroidism following Hemi-thyroidectomy. Maximum number of cases were diagnosed within 18 weeks of surgery.

Conclusion: Incidence of Hypothyroidism following Hemithyroidectomy in our study is quite high amounting to $20.4 \%$ which includes both sub-clinical as well as overt cases. Overt cases being treated with Levothyroxine, subclinical cases had been followed up carefully.

Keywords: Hemi-thyroidectomy, Hypothyroidism, TSH (Thyroid Stimulating Hormone), F T3(Free triiodothyronine), FT4, (Free Thyroxine).
\end{abstract}

\section{Introduction}

Thyroid hormones are very much essential for survival. Their deficiency produces slowing of general metabolic processes of body resulting in serious systemic diseases and complications. There are so many causes of hypothyroidism like congenital enzyme deficiency for synthesis of thyroid hormones, auto- immune disorders, hypothalamic/pitutary disorders, metabolic diseases (amyloidosis, haemo-chromatosis) head and neck irradiation, radio-iodine ablation, surgical operations on thyroid, drugs (such as tyrosine kinase inhibitors, iodides, sulfonamides, anti-thyroid drugs, lithium, amiodarone, cytokines \& goitrogenes etc). But, diagnosis of hypothyroidism is mostly made by TFT (Thyroid function test )which includes estimation of free thyroxine (FT4), free tri-iodothyronine (FT3) and Thyroid stimulating hormones(TSH) in the serum although there are certain clinical features like 
growth retardation, weight gain, muscle cramps, fatigue, hoarseness of voice, menstrual disorders in females, enlargement of thyroid, puffiness of face, carpal tunnel syndrome, loss of hairs, delayed tendon jerks which create high degree of suspicion in the mind of clinicians. ${ }^{1}$ An elevated level of TSH in presence of low FT4 establishes the diagnosis of hypothyroidism. But in subclinical hypothyroidism, a normal FT4 level is usually found in addition to elevated $\mathrm{TSH}^{2}$ Hypothyroidism developing after hemithyroidectomy (ie excision of affected thyroid lobe, isthmus and pyramidal lobe) is an underappreciated entity. This condition can very well be diagnosed by careful medical history, thorough clinical examination and routine TFT from a reliable laboratory. Early detection of potentially hazardous post-operative complications will prevent further progress of hypothyroidism as well as recurrent thyroid disease in the contralateral lobe.

\section{Materials and Methods}

This study was conducted in the department of Experimental/Endocrine Surgery of SCB Medical College \& Hospital, Cuttack (Odisha) from 2012 to 2018 in which total number of 480 patients above the age of 14years who had undergone hemi-thyroidectomy with pre-operatively normal thyroid function test (TFT) were included. Patients below14 years and above 80 years of age, pre-op diagnosis of hypo/hyper thyroidism, thyroid malignancy and history of taking medicines known to alter thyroid hormones/TSH level were excluded from the study.TFT (FT3,FT4 \&TSH) was routinely performed in all cases included in the study at 12 weeks, 18 weeks and 24 weeks following hemi-thyroidectomy. Patients with serum TSH value more than 6 micro IU/ml with clinical features were diagnosed as hypothyroid. Those having normal FT4 (Table No-1) with raised TSH level (more than the higher limit of reference range) were termed as subclinical hypothyroidism and were carefully followed up for developing overt hypothyroidism. ${ }^{3}$

Table No-1: Reference values of thyroid function test

\begin{tabular}{|l|c|}
\hline Test & Reference values \\
\hline FT3 & $3.10-6.80 \mathrm{pmol} / \mathrm{l}$ \\
\hline FT4 & $12.0-22.0 \mathrm{pmul} / \mathrm{l}$ \\
\hline TSH & $0.27-4.20 \mathrm{micro} \mathrm{IU} / \mathrm{ml}$ \\
\hline
\end{tabular}

\section{Results}

Out of 480 numbers of patients undergoing hemithyroidectomy, 72(15\%) patients developed overt hypothyroidism and $26(5.4 \%)$ patients developed sub-clinical hypothyroidism. (Table No: 2) Thus total number of patients who developed hypothyroidism (over and sub-clinical) were 98 (20.4\%). In our study, females predominated $(77.5 \%)$ over males and patients in the age group of 14 years to 40 years were more prone to develop hypothyroidism.(Table No: $3 \& 4$ )

Table No -2: No \& Percentage of cases of Hypothyroidism after Hemi-thyroidectomy

\begin{tabular}{|l|c|c|c|c|}
\hline \multirow{2}{*}{ Diagnosis } & \multicolumn{4}{|c|}{ No. of cases \& percentage } \\
\cline { 2 - 5 } & $\begin{array}{c}12 \\
\text { weeks } \\
\text { post- } \\
\text { op }\end{array}$ & $\begin{array}{c}18 \\
\text { weeks } \\
\text { post- } \\
\text { op }\end{array}$ & $\begin{array}{c}24 \\
\text { weeks } \\
\text { post- } \\
\text { op }\end{array}$ & Total \\
\hline $\begin{array}{l}\text { Subclinical } \\
\text { Hypothyroidism }\end{array}$ & 8 & 12 & 6 & $26(5.4 \%)$ \\
\hline $\begin{array}{l}\text { Overt } \\
\text { Hypothyroidism }\end{array}$ & 24 & 36 & 12 & $72(15 \%)$ \\
\hline
\end{tabular}

Table No- 3: Sex distribution among Hypothyroid patients

\begin{tabular}{|l|c|c|}
\hline Sex & No. of patients & Percentage. \\
\hline Male & 22 & 22.4 \\
\hline Female & 76 & 77.5 \\
\hline
\end{tabular}

Table No -4 Age distribution among Hypothyroid patients

\begin{tabular}{|l|c|c|}
\hline Age (yr) & No. of patients & Percentage \\
\hline $14-40$ & 62 & $63.2 \%$ \\
\hline $41-80$ & 36 & $36.7 \%$ \\
\hline
\end{tabular}

\section{Discussion}

Development of hypothyroidism following hemithyroidectomy ranges from 5\%-49\% as reported by various authors. ${ }^{4}$ Wide variation in the 
incidence of hypothyroidism reported in different studies mostly depends on period of follow-up and upper limit of TSH value for diagnosing overt hypothyroidism. Usually, after hemithyroidectomy the pituitary-thyroid axis undergoes adaptation and there is increase in serum TSH level at one month following hemithyroidectomy in most of cases. ${ }^{5}$ However, there are many risk factors which predispose the patient to develop hypothyroidism followings hemithyroidectomy like higher normal range of pre-op TSH level, anti-TPO antibody in serum, lymphocytic infiltration in thyroid gland on histopathologic examination, pathological lesion in the retained thyroid lobe and generalized metabolic diseases. (i.e amyloidosis, haemochromatosis) ${ }^{6}$

In this study, maximum number of hypothyroid cases had been detected within 18 weeks of hemithyroidectomy and all the patients with features of overt hypothyroidism were treated with levothyroxine. ${ }^{7}$

\section{Conclusion}

In our study, total incidence of hypothyroidism following hemithyroidectomy is $20.4 \%$ which includes overt (15\%) and sub- clinical (5.4\%) hypothyroidism. Hormone replacement therapy by Levo-thyroxine in appropriate dosage is recommended in all cases of overt hypothyroidism to prevent further complications. However, subclinical hypothyroid cases require prolonged follow-up.

\section{References}

1. Surks M.I. Oritz E., Daniels E.H. et al. Sub-clinical Thyroid disease: Scientific Review and Guide- lines for Diagnosis and Management. JAMA 2004; 291:228-38

2. Ladenson P.W., Singer P.A., AinKB et al. American Thyroid Association guidelines for detection of thyroid dysfunction. Arch Intern Med 2000; 160:1573-5.

3. Meena Said, Vicki Chiu, Philip I. Haigh. Hypothyroidism after Hemi- thyroidectomy. World J. Surg 2013, vol.37/Issue 12 .

4. Dongbin Ahn, Jin Ho Sohn \& Jae Han Jeon. Hypothyroidism fallowing Hemithyroidectomy: Incidence, Risk factors \& Clinical Characteristics. J. Clin Endocrinol Metab 2016; 101(4): 1429-1436.

5. Piper H.G. Bugis S.P. Wilkins G.E., Walker B.A., Wiseman S.,Baliski C.R. Detecting \& defining Hypothyroidism after Hemi-thyroidectomy. Am J. Surg 2005; 189 (5):587-91.

6. Miller F.R., Paulson D., Prihoda T.J., Otto R.A. Risk factors for development of Hypothyroidism after Hemithyroidectomy. Arch Otolaryngol Head Neck Surg 2006, 132: 36-38.

7. Koh W.Y., Lee S.W., Choi E.C., Lee J. D., Mok J.O.,Kim H.K, Koh E.S., Lee J.Y., Kim S.C. Prediction of Hypothyroidism after Hemi-thyroidectomy: a biochemical \& pathological analysis. Eur Arch Otorhinolaryngol 2008, 265: 453-457. 